Original Research Article

\title{
A study on prescribing errors in in-patients of a corporate tertiary care hospital in North India
}

\author{
Ashish Yadav, Mohammed R. Rashed*
}

Department of Pharmacology, MES Medical College,

Perinthalmanna, Kerala, India

Received: 28 May 2019

Revised: 29 June 2019

Accepted: 02 July 2019

\section{*Correspondence to:}

Dr. Mohammed R. Rashed, Email: rashidrafi@gmail.com

Copyright: (C) the author(s), publisher and licensee Medip Academy. This is an openaccess article distributed under the terms of the Creative Commons Attribution NonCommercial License, which permits unrestricted noncommercial use, distribution, and reproduction in any medium, provided the original work is properly cited.

\begin{abstract}
Background: Prescribing errors are a subset of medication errors which have a potential for grave harm to the patient. Identification and acknowledgement of such errors can ameliorate much of this danger. Studies of prescribing errors are sparse in India. Such studies, whatever have been conducted, mainly focus on the out-patients or the patients on discharge. Hence, this study was undertaken to study the prescribing errors in prescriptions generated for patients admitted in wards of a corporate hospital in North India.

Methods: The prescriptions for in-patients admitted in wards were analyzed for different types of prescribing errors in individual drug orders and prescription as a whole.

Results: The prescribing error rate was found to be $3.3 \%$ in this study. Of all errors, errors leading to delays in patient care (i.e. Errors of prescription writing) (54.54\%) and erroneous copying of the prescription to the drug chart by junior/ resident doctors (Transcription errors) (31.31\%) were found to be the major causes of prescribing errors in this study. Of the former category, prescribing a wrong strength $(24.24 \%)$ and illegible drug orders $(12.12 \%)$ were the most numerous error subtypes. Errors leading to sub-optimal patient care (i.e. Errors of decision making) were least identified of which Therapeutic duplication $(12.12 \%)$ was the most common subtype.

Conclusions: The error rate found in this study is comparable to the data available from developed countries. However, there are significant differences in the occurrences of error subtypes found in this study as compared to the studies of the west.
\end{abstract}

Keywords: Indian, In-patients, Medication errors, Prescribing errors, Prescription errors, Transcription errors

\section{INTRODUCTION}

Medication errors are errors related to medication use for patient care. These errors can be introduced anywhere from the point of generation of the drug order by the physician, to dispensing of the drug by the pharmacist to the administration of the drug by the nurse.

A medication error is termed prescribing error, "when as a result of a prescribing decision or prescription writing process, there is an unintentional significant reduction in the probability of treatment being timely and effective or increase in the risk of harm when compared with generally accepted practice". 1

Prescribing errors pose a significant concern in patient care. ${ }^{2}$ Prescription error rates for hospital inpatients have been reported to be as low as $0.4-1.9 \%$ according to old estimates, to as high as $7-14.7 \%$ of all drug orders according to new ones in the developed world..$^{3-9}$ Not only can these errors increase the cost of treatment and length of hospital stay for the patient, but also mortality rate. ${ }^{10-11}$ 
The prescription error estimates in Indian context are largely lacking probably due to non-uniform prescription practices. Very few studies in India have focused on prescribing errors per se and those which have, have been undertaken on out-patients and patients being discharged. The error rates in estimated by these studies stand at staggering $65-90 \% .^{12,13}$

This study was undertaken with the aim of finding prescribing errors in drug orders for in-patients of a corporate tertiary care hospital of North India and evaluating them in a similar way as done in studies on inpatients in the developed world.

\section{METHODS}

\section{Study area and workflow description}

This study was conducted in a corporate tertiary care hospital in North India. The prescriptions for patients admitted in general wards of the hospital were considered for the study. In this hospital, the consultant or doctor-incharge writes the prescription order for the patient admitted in ward in the daily notes of the patient. The individual drug orders from this prescription order are copied to designated spaces of the drug chart in the patient's file by a junior or resident doctor. The drugs for the patients are ordered from the pharmacy by the nurses according to the drug chart.

\section{Inclusion and Exclusion Criteria}

Only the prescriptions and drug orders in drug charts, which were written for the patients admitted in the general wards of the hospital during routine rounds, were considered for this study. Drug orders for such patients arising out of any emergency were not included.

\section{Data Collection}

Prescriptions and drug charts which met the inclusion criteria were considered for this study and the same were collected for a period of one month. The collected prescriptions and drug charts were segregated into individual drug orders. The drug orders were scrutinized for the presence of errors. If prescribing error was identified, it was classified according to type and subtype for further analysis and inference.

\section{Terms used for this study}

\section{Prescription}

A physician's order for medications for a patient written by him/her in the daily doctor notes which ended up on the drug chart was considered a prescription.

A prescription could have one or more drug orders. Only and only medication order part of the prescription was considered. Presence or absence of other parts of the prescription (viz. symbol $\mathrm{Rx}$ ) was not taken into consideration to maintain focus of this study.

\section{Drug order}

Individual order for a single drug from the prescription was considered a drug order.

\section{Prescribing error}

Any error identified in drug order, prescription or drug chart of the patient's file which could jeopardize either timely administration of drugs or judicious and optimal use of drugs in accordance with the condition of the patient was considered a prescribing error.

\section{Transcribing error}

Any error in copying prescription order into the drug chart by the junior or resident doctors was termed transcription error.

\section{Classification of prescribing errors:}

Classification of prescribing errors given by Dean et al, ${ }^{1}$ has been used in a modified form in this study. The errors were classified on whether they lead to delay in following the instruction by the doctor for the drug (Errors in prescription writing) or injudicious and sup-optimal use of the drug for the given patient (Errors in decision making). In addition, transcribing errors, which though can result in any of the above two types of errors, were considered as a separate entity for this study. The classification and types of errors considered for the study are listed in Table 1.

\section{RESULTS}

In this study 50 general ward beds were covered for the study during which 223 patients were allocated those beds at some point during the course of the study. 840 prescriptions were collected amounting to 2925 drug orders. The drug orders and prescriptions were scanned for errors as per the study criteria. 99 prescribing errors were identified.

Inferring from the above data, each general ward bed was occupied by 4.46 patients in a month on an average with an average stay of 6.73 days. Average number of prescriptions for each general ward patient was 3.76 and average number of drug orders per prescription stood at 3.48 per prescription. Prescribing error rate was found to be $3.3 \%$ in this study.

More than half of all prescribing errors were identified due to errors in prescription writing ie errors causing delays $(n=54 ; 54.55 \%)$. Transcribing errors was the next big error group identified at $\mathrm{n}=31(31.31 \%)$. Errors in decision making leading to suboptimal treatment were the least in count $(n=14 ; 14.14 \%)$ (Figure 1, Table 2). Of the errors in prescription writing, ambiguous drug orders made up the bulk $(n=33 ; 33.33 \%)$ followed by illegible drug orders $(n=12$; $12.12 \%)$ and incomplete drug orders $(n=9 ; 9.09 \%)$. Almost 
all the errors in decision making were due to therapeutic duplication $(\mathrm{n}=12 ; 12.12 \%)$. However, 2 (2.02\%) orders within the scope of inappropriate drug errors were identified (Figure 2, Table 2). Considering the individual error subtypes, most of the prescribing errors $(n=24 ; 24.24 \%)$ were found to be due to discrepancy in the strength for the drug ordered (Error subtype 1.2.3; Table-2, Figure-3). Next in numbers were the individual transcribing errors at $\mathrm{n}=18(18.18 \%)$ and $\mathrm{n}=13(13.13 \%)$ respectively for error subtypes 3.1.2 and 3.1.1 (Table 2, Figure 3).

Table 1: Classification of Prescribing Errors used in this study. Errors are primarily classified as to whether they cause delay in administration or cause sub-optimal treatment. Transcribing errors, although can cause either of the above two types of errors, are attributed in this study only to the erroneous copying by junior or resident doctors and hence considered as a separate category. The scope of error denotes the scenarios considered for the error type.

\begin{tabular}{|c|c|c|}
\hline Broad Category & Error Type & Scope \\
\hline \multirow{3}{*}{$\begin{array}{l}\text { 1. Errors causing } \\
\text { delays (Errors in } \\
\text { prescription writing) }\end{array}$} & $\begin{array}{l}\text { 1.1. Incomplete drug } \\
\text { order }\end{array}$ & $\begin{array}{l}\text { A drug order lacking in one or more of the following: } \\
\text { 1.1.1. Dosage form } \\
\text { 1.1.2. Drug name } \\
\text { 1.1.3. Strength (for drugs available in more than one strength) } \\
\text { 1.1.4. Dose } \\
\text { 1.1.5. Route of administration } \\
\text { 1.1.6. }\end{array}$ \\
\hline & $\begin{array}{l}\text { 1.2. Ambiguous drug } \\
\text { order }\end{array}$ & 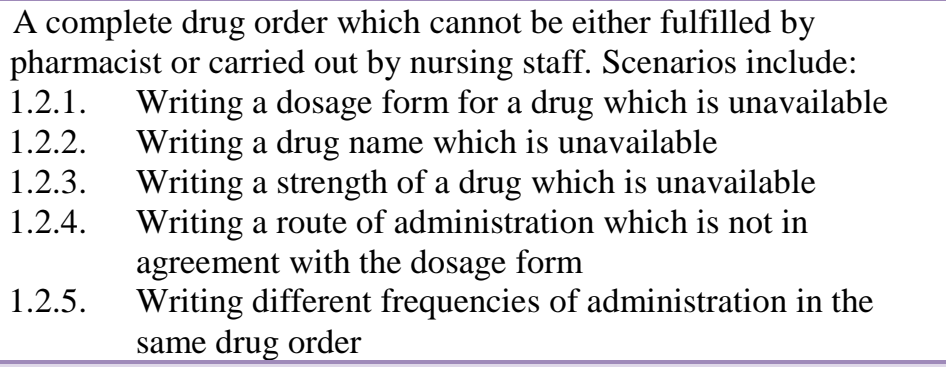 \\
\hline & $\begin{array}{l}\text { 1.3. Illegible drug } \\
\text { order }\end{array}$ & $\begin{array}{l}\text { Any drug order of which any part is: } \\
\text { 1.3.1. Could not be read } \\
\text { 1.3.2. Difficult to be read or understood } \\
\text { 1.3.3. Could be read leading to dispensing or administration in a } \\
\text { manner other than intended }\end{array}$ \\
\hline \multirow{4}{*}{$\begin{array}{l}\text { 2. Errors causing } \\
\text { suboptimal treatment } \\
\text { or harm (Errors in } \\
\text { decision making) }\end{array}$} & $\begin{array}{l}\text { 2.1. Contraindicated } \\
\text { drug order }\end{array}$ & $\begin{array}{l}\text { A drug order given in spite of: } \\
\text { 2.1.1. Documented allergy of the patient to that drug } \\
\text { 2.1.2. Contraindication to that drug for the patient's given } \\
\text { clinical condition }\end{array}$ \\
\hline & 2.2. Inappropriate drug & $\begin{array}{l}\text { A prescribed drug which is: } \\
\text { 2.2.1. Inappropriate for the patient's renal or hepatic function } \\
\text { provided that better alternatives exist } \\
\text { 2.2.2. Totally unrelated to the patient's given clinical condition } \\
\text { 2.2.3. Prescribed with an incompatible diluent (for drugs to be } \\
\text { infused) }\end{array}$ \\
\hline & 2.3. Inappropriate dose & $\begin{array}{l}\text { A drug prescribed in a dose which is: } \\
\text { 2.3.1. High or low for the drug's daily dose range for any } \\
\text { condition } \\
\text { 2.3.2. High or low for patient's renal function }\end{array}$ \\
\hline & $\begin{array}{l}\text { 2.4. Therapeutic } \\
\text { duplication }\end{array}$ & $\begin{array}{l}\text { A prescription order which contains more than one: } \\
\text { 2.4.1. Drug orders / Brands containing the same ingredient } \\
\text { drugs } \\
\text { 2.4.2. Drug orders / Brands containing different ingredient } \\
\text { drugs of the same category, whereby mechanism of } \\
\text { action of drugs is same or similar }\end{array}$ \\
\hline $\begin{array}{l}\text { 3. Errors caused due to } \\
\text { erroneous copying of } \\
\text { prescription by junior } \\
\text { or resident doctor }\end{array}$ & 3.1. Transcribing Error & $\begin{array}{l}\text { Errors in copying prescription to the drug chart by junior or } \\
\text { resident doctor causing: } \\
\text { 3.1.1. Delay in administration } \\
\text { 3.1.2. Suboptimal treatment or harm }\end{array}$ \\
\hline
\end{tabular}


Table 2: Incidence of different types of errors. Those error types, for which no error was identified, have been omitted from the table.

\begin{tabular}{|c|c|c|c|c|}
\hline $\begin{array}{l}\text { Broad error } \\
\text { category }\end{array}$ & Error type & Error sub-type (refer Table-1) & Incidence (n) & $\begin{array}{l}\text { Incidence } \\
\%\end{array}$ \\
\hline \multirow{11}{*}{$\begin{array}{l}\text { Errors causing } \\
\text { delays (Errors of } \\
\text { prescription writing) } \\
(\mathrm{n}=54 ; 54.54 \%)\end{array}$} & \multirow{3}{*}{$\begin{array}{l}\text { Incomplete drug order } \\
(\mathrm{n}=9 ; 9.09 \%)\end{array}$} & No dosage form mentioned (1.1.1) & 1 & $2.02 \%$ \\
\hline & & No strength mentioned (1.1.3) & 6 & $6.06 \%$ \\
\hline & & No frequency mentioned (1.1.6) & 1 & $1.01 \%$ \\
\hline & \multirow{5}{*}{$\begin{array}{l}\text { Ambiguous drug order } \\
(\mathrm{n}=33 ; 33.33 \%)\end{array}$} & Wrong dosage form (1.2.1) & 3 & $3.03 \%$ \\
\hline & & Wrong drug name (1.2.2) & 2 & 2.02 \\
\hline & & Wrong strength (1.2.3) & 24 & $24.24 \%$ \\
\hline & & Wrong route $(1.2 .4)$ & 3 & $3.03 \%$ \\
\hline & & Wrong frequency $(1.2 .5)$ & 1 & $1.01 \%$ \\
\hline & \multirow{3}{*}{$\begin{array}{l}\text { Illegible drug order } \\
(\mathrm{n}=12 ; 12.12 \%)\end{array}$} & Unreadable drug order (1.3.1) & 8 & $8.08 \%$ \\
\hline & & Difficult to read (1.3.2) & 2 & $2.02 \%$ \\
\hline & & Misunderstood drug order (1.3.3) & 2 & $2.02 \%$ \\
\hline \multirow{4}{*}{$\begin{array}{l}\text { Error causing } \\
\text { suboptimal treatment } \\
\text { (Errors of decision } \\
\text { making) } \\
(\mathrm{n}=14 ; 14.14 \%)\end{array}$} & \multirow{2}{*}{$\begin{array}{l}\text { Inappropriate drug } \\
(\mathrm{n}=2 ; 2.02 \%)\end{array}$} & Unrelated drug order (2.2.2) & 1 & $1.01 \%$ \\
\hline & & Wrong diluent $(2.2 .3)$ & 1 & $1.01 \%$ \\
\hline & \multirow{2}{*}{$\begin{array}{l}\text { Therapeutic duplication } \\
(\mathrm{n}=12 ; 12.12 \%)\end{array}$} & Drug molecule duplicated (2.4.1) & 9 & $9.09 \%$ \\
\hline & & Drug category duplicated (2.4.2) & 3 & $3.03 \%$ \\
\hline \multirow{2}{*}{$\begin{array}{l}\text { Errors of copying } \\
\text { prescription by the } \\
\text { junior or resident } \\
\text { doctor } \\
(\mathrm{n}=31 ; 31.31 \%)\end{array}$} & \multirow{2}{*}{$\begin{array}{l}\text { Transcribing error } \\
(\mathrm{n}=31 ; 31.31 \%)\end{array}$} & $\begin{array}{l}\text { Transcription leading to delay } \\
\text { (3.1.1) }\end{array}$ & 13 & $13.13 \%$ \\
\hline & & $\begin{array}{l}\text { Transcription leading to suboptimal } \\
\text { Tt. (3.1.2) }\end{array}$ & 18 & $18.18 \%$ \\
\hline
\end{tabular}

Prescriptions containing more than one drug order or brands with same ingredient drugs (Error subtype 2.4.1) and illegible handwriting wherein a part of a drug order was totally unreadable (Error subtype 1.3.1) were also significant contributors to the error numbers at $n=9$ $(9.09 \%)$ and $n=8(8.08 \%)$ respectively (Table-2, Figure-3). Many error subtypes were not identified in this study especially those pertaining to errors in decision making while some were identified in low incidences ranging from $\mathrm{n}=1$ to $\mathrm{n}=5$ (Table-2, Figure-3).

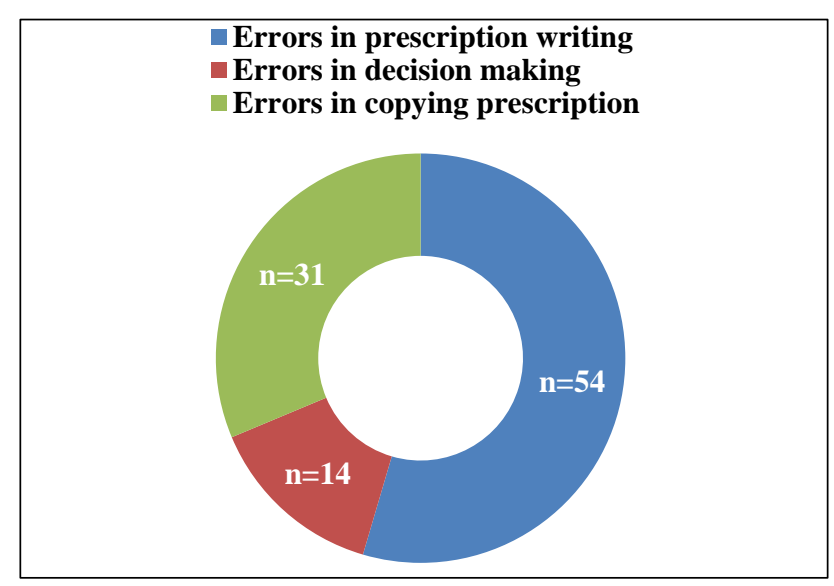

Figure 1: Prescribing error incidence. Errors in prescription writing and Transcribing errors constituted about $85 \%$ of all errors.

\section{DISCUSSION}

The decision to include prescriptions generated in general ward only was taken considering it to represent worst case scenario. This assumption was made on the basis of these patients requiring lesser time and thought process from the physicians during general rounds given their better overall health.

This study considers transcribing errors as a separate entity as compared to the classification suggested by Dean ${ }^{1}$ because in this hospital the source of all transcribing errors was resident or junior doctors. Considering these errors as a separate entity in this setup was prudent as the remedial action of these errors would have specific set of prescribers as target for remedial action.

The prescribing error rate of $3.3 \%$ found in this study falls in the range of other such studies done on in-patients wherein the error rate has been reported from $1.5 \%$ to $15 \% .^{8,14-16}$ The reported prescribing error rates in studies done on out-patients have been much higher i.e. $65 \%$ or greater. $^{12,13,17-19}$ The reason for such stark contrast in studies done on in-patient's vs out-patients is that latter also look into the additional variables such as super inscription, diagnosis, anthropometric data, symbol Rx, duration of the treatment etc. which drives the prescribing error rate northwards. 
The error patterns of this study quite match with those of other studies on prescribing errors. The most common errors in this study are those which lead to delay in treatment i.e. errors in prescription writing. The studies of Ryan et al, and Ridley et al, also indicate similar pattern. When adjusted to criteria of this study, studies done on outpatients also report errors in prescription writing as the major contributor for errors. ${ }^{8,12,16-19}$ Also, this study is in agreement with illegibility as a cause of prescribing error $(12.12 \%)$ with the studies of Ryan et al, (9.6\%) and Mohan et al, $(13.3 \%){ }^{8,12}$

The error sub-type identified in this study to be the largest contributor of prescribing errors was mentioning strength for a drug which was not available in the market. Hitti et al, have mentioned this error in their study but not others. ${ }^{17}$ Probably those authors included this error in the broader classification of errors in prescription writing and probably this error was not significant in those studies.

This error can be commonly presumed to be associated with those drugs, the oral and parenteral doses of which differ viz., ciprofloxacin, ranitidine etc. However, in this study, such association was not found, and this error spanned various drugs pointing to sheer carelessness while prescribing.

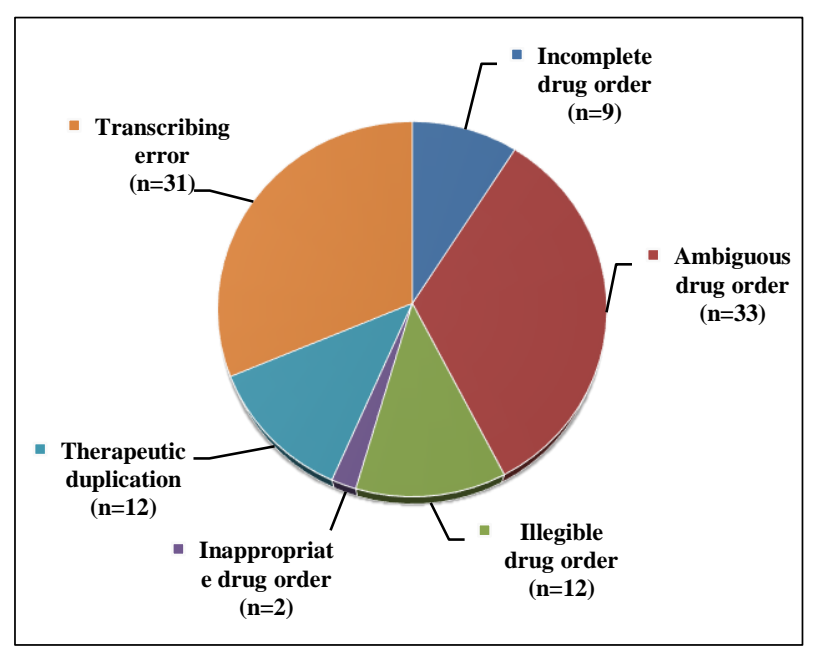

Figure 2: Error incidence by error type. Ambiguous drug orders and Transcribing errors were responsible for around $65 \%$ of all Prescribing errors.

This study also contrasts with other studies when errors in decision making are considered especially the incidence of inappropriate dose error. This difference is explained by the criteria of this study which considered the overall dose range of a drug for any indication rather than formulary specified dose for a particular diagnosis. Another difference was that this study did not evaluate omissions, i.e. patient's long term home medications missing in their prescriptions or if a drug was omitted even when indicated. This results in such errors being significant contributors in western studies $7-9,15,16,19$ but lacking in this study. Therapeutic duplication has been reported by various authors in their study but the incidence in their study is quite low ranging from 1 to $6.4 \%$ contrasting with $12.12 \%$ in this study. ${ }^{7,8,16,17}$ Most of these errors in this study were due to prescribing of different brands containing the same ingredient drugs. Few cases were due to the same category drugs being prescribed in the same prescription. This error subtype in this study was largely identified in scenarios, where a team of prescribers was involved in the patient healthcare rather than a single prescriber.

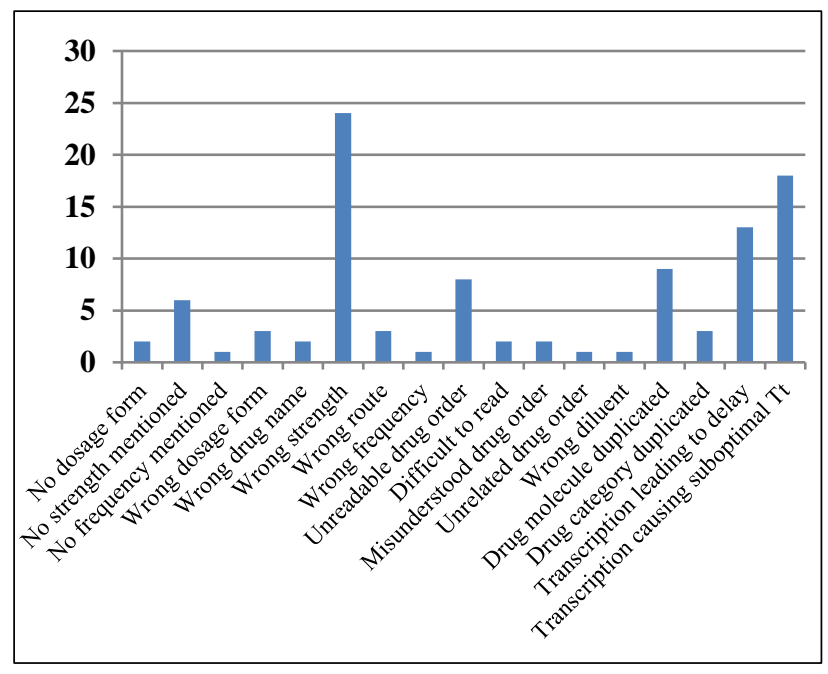

Figure 3: Incidence of individual error subtypes. Mentioning an unavailable strength along with transcription errors were the most common subtypes.

Lastly, transcription errors have been acknowledged by many studies and their incidence in western studies is reported to be low ranging from $1-4.6 \% .^{8,14,16}$ This again is in contrast with this study, where transcription errors were one of the most common errors encountered. One reason for this anomaly is that the prescribers in the west, probably, are more sincere in writing their prescriptions themselves in the drug chart rather than the junior or resident doctors as was the case in this study.

\section{Other outcomes of this study}

Although out of scope of this article, the authors would like to highlight the benefits of this study's data collection and analysis. The data on errors helped identify error prone prescribers. The hospital management was provided this data which then planned counselling meetings with these prescribers so as to bring down such occurrences. Also, sensitization sessions of all prescribers were planned by the hospital management for errors arising due to illegible handwriting and therapeutic duplication citing examples from this study.

Since transcribing errors by junior or resident doctors was a significant contributor of total prescribing errors, hospital management included sensitization on these errors in the orientation class on induction of junior or resident doctors in the hospital. 


\section{Scope of further research}

Further studies in India on the lines of this study, not only encompassing non-critical inpatients as this study, but also critical and outpatient populations can help collect the statistics of prescribing errors in India which, as of now, is sparse. Also, such studies open the avenues of similarly patterned studies of the impact of interventions on prescribing errors after the primary study has identified the gaps and interventions have been applied. Another area of study would be expanding scope of such studies to include dispensing and administration errors along with prescribing errors to have a clearer picture of medication errors overall.

Funding: No funding sources

Conflict of interest: None declared

Ethical approval: Not required

\section{REFERENCES}

1. Dean B, Schachter M, Vincent C, Barber N. Prescribing errors in hospital inpatients: their incidence and clinical significance. Qual Saf Health Care. 2002 Dec;11(4):340-4.

2. WHO. The third WHO Global Patient Safety Challenge: Medication Without Harm [Internet]. WHO. Available at: http://www.who.int/patientsafety/medicationsafety/en/. 18 May 2019.

3. Folli HL, Poole RL, Benitz WE, Russo JC. Medication error prevention by clinical pharmacists in two children's hospitals. Pediatr. 1987 May 1;79(5):71822.

4. Blum KV, Abel SR, Urbanski CJ, Pierce JM. Medication error prevention by pharmacists. Am J Hosp Pharm. 1988 Sep 1;45(9):1902-3.

5. Lesar TS, Briceland L, Stein DS. Factors related to errors in medication prescribing. JAMA. 1997 Jan 22;277(4):312-7.

6. An in Depth Investigation into Causes of Prescribing Errors by Foundation Trainees in Relation to Their Medical Education EQUIP Study. AHRQ Patient Safety Network. Available at: https://psnet.ahrq.gov/resources/resource/17269/anin-depth-investigation-into-causes-of-prescribingerrors-by-foundation-trainees-in-relation-to-theirmedical-education-equip-study. 18 May 2019.

7. Franklin BD, Reynolds M, Shebl NA, Burnett S, Jacklin A. Prescribing errors in hospital inpatients: a three-centre study of their prevalence, types and causes. Postgrad Med J. 2011 Nov 1;87(1033):739-45.

8. Ryan C, Ross S, Davey P, Duncan EM, Francis JJ, Fielding S, et al. Prevalence and Causes of Prescribing Errors: The PRescribing Outcomes for Trainee Doctors Engaged in Clinical Training (PROTECT) Study. Berthold HK, editor. PLoS ONE. 2014 Jan 3;9(1):e79802.
9. Seden K, Kirkham JJ, Kennedy T, Lloyd M, James S, Mcmanus A, et al. Cross-sectional study of prescribing errors in patients admitted to nine hospitals across North West England. BMJ Open. 2013;3(1):e002036.

10. Bates DW, Spell N, Cullen DJ, Burdick E, Laird N, Petersen LA, et al. The Costs of Adverse Drug Events in Hospitalized Patients. JAMA. 1997 Jan 22;277(4):307-11.

11. Elliot R.A., Camacho E., Campbell F., Jankovic D., James M.M.S., Kaltenthaler E, et al. Prevalence and economic burden of medication errors in the NHS in England. Available at: http://www.eepru.org.uk/prevalence-and-economicburden-of-medication-errors-in-the-nhs-in-england2/. 18 May 2019.

12. Mohan P, Sharma AK, Panwar SS. Identification and quantification of prescription errors. Med J Armed Forces Ind. 2014 Apr;70(2):149-53.

13. Shelat PR, Kumbar SK. Analysis of Outdoor Patients' Prescriptions According to World Health Organization (WHO) Prescribing Indicators Among Private Hospitals in Western India. J Clin Diagn Res. 2015 Mar;9(3):FC01-4.

14. Dean B, Schachter M, Vincent C, Barber N. Prescribing errors in hospital inpatients: their incidence and clinical significance. Qual Saf Health Care. 2002 Dec;11(4):340-4.

15. Franklin BD, Puaar S. What is the impact of introducing inpatient electronic prescribing on prescribing errors? A naturalistic stepped wedge study in an English teaching hospital. Health Informatics J. 2019 Mar 18;146045821983311.

16. Ridley SA, Booth SA, Thompson CM, Intensive Care Society's Working Group on Adverse Incidents. Prescription errors in UK critical care units. Anaesthesia. 2004 Dec;59(12):1193-200.

17. Hitti E, Tamim H, Bakhti R, Zebian D, Mufarrij A. Impact of Internally Developed Electronic Prescription on Prescribing Errors at Discharge from the Emergency Department. West J EM. 2017 Aug 7;18(5):943-50.

18. Alvarado AC, Ossa GX, Bustos ML. Errores en las recetas médicas y en la preparación de estas en farmacia de pacientes ambulatorios: El caso del Hospital de Nueva Imperial. Rev méd Chile. 2017 Jan;145(1):33-40.

19. Babatunde KM, Akinbodewa AA, Akinboye AO, Adejumo AO. Prevalence and pattern of prescription errors in a Nigerian kidney hospital. Ghana Med J. 2016 Jan 16;50(4):233.

Cite this article as: Yadav A, Rashed MR. A study on prescribing errors in in-patients of a corporate tertiary care hospital in north India. Int J Basic Clin Pharmacol 2019;8:1855-60. 